\title{
Upper gastrointestinal endoscopy performed by nurses: scope for the future?
}

\author{
S Smale, I Bjarnason, I Forgacs, P Prasad, M Mukhood, M Wong, A Ng, H E Mulcahy
}

Gut 2003;52:1090-1094

\begin{abstract}
Background: Previous researchers have shown that non-medical endoscopists can perform lower gastrointestinal endoscopy as safely and effectively as medical staff. However, it is not known if upper gastrointestinal endoscopy performed by medical and non-medical endoscopists in clinical practice yields similar results in terms of performance, patient discomfort, and satisfaction.

Aim: To determine differences in the yield of diagnosis for significant disease during upper gastrointestinal endoscopy performed by nurse and medical endoscopists and to measure patient discomfort, satisfaction, and attitudes towards future endoscopy.

Patients: This two part study included 3009 patients in a retrospective analysis and 480 in a prospective study.

Methods: The first part of the study assessed indications for endoscopy, diagnoses, and procedures performed by medical and nurse endoscopists. In a second prospective study, 480 patients were included to determine the association between endoscopist type and sedation, patient anxiety, discomfort, satisfaction, and attitudes towards future sedation. Results: No patient refused endoscopy by either a nurse or medical endoscopist and there were no complications in either group. Nurses performed 1487 procedures and reported fewer endoscopies as "normal" than medical staff ( $p=0.006)$. Multivariate analysis showed that male sex, older age, inpatient status, dysphagia, and gastrointestinal bleeding, but not endoscopist type, were all associated with significant disease. In relation to discomfort and satisfaction, a similar proportion of patients received sedation in both groups $(p=0.81)$. There were no differences in pre-procedure anxiety $(p=0.61)$, discomfort during intubation $(p=0.97)$, discomfort during examination $(p=0.90)$, or post-procedure examination rating $(p=0.79)$ in patients examined by medical or nurse endoscopists. Conclusion: Experienced nurses perform routine diagnostic gastroscopy safely in everyday clinical practice and with as little discomfort and as much patient satisfaction as medical staff.
\end{abstract}

See end of article for authors' affiliations

Dr H Mulcahy, St Vincer University Hospital, Elm

Park, Dublin 4, Ireland; email:

hemulc@hotmail.com

Accepted for publication 28 January 2003

\section{SUBJECTS AND METHODS}

The first part of this clinical outcomes study was a retrospective database (Endoscribe) analysis of routine diagnostic endoscopies to determine the indications and diagnoses for procedures performed by medical and nurse endoscopists. The

study included 3009 consecutive patients (mean age 58 years (range 18-100): 1609 females) attending a single unit at King's College Hospital, London, between April 2000 and December 2001. Fifteen surgical and medical gastroenterologists and two nurse endoscopists took part in the study. Patients under 18 years and those with incomplete data were excluded from the study. In addition, patients undergoing emergency endoscopy, those requiring a therapeutic procedure, and those attending the specialist hepatology service within the hospital were excluded as these patients were not expected to be routinely endoscoped by nurse endoscopists. The nurse endoscopists did perform routine diagnostic endoscopy on patients with a prior history of haematemesis or melaena, but only on those with no active symptoms or signs and who were not anaemic.

The aim of the second part of the study was to determine the association between endoscopist type and pre-procedure sedation, patient anxiety, discomfort during the procedure, satisfaction with the procedure, and attitudes towards future sedation. A total of 480 of the above patients (mean age 55 years (range 18-96): 273 female) were included in this prospective study. Seven surgical and medical gastroenterologists and both nurse endoscopists took part in the study. Patients completed a two part questionnaire, previously described and validated. ${ }^{6-8}$ Anxiety and discomfort scores were assessed on a 10 point visual analogue scale (0, none; 10, unbearable). These studies were approved by the King's College Hospital Research Ethics Committee.

The nurse endoscopists were employed and indemnified by King's College Hospital NHS Trust. Both underwent a period of training on practical, theoretical, medico-legal, and ethical 
Table 1 Clinical features and endoscopic findings in 3009 patients attending for routine diagnostic gastroscopy stratified by endoscopist type (patients whose examinations were unsuccessful were excluded from the latter analyses)

\begin{tabular}{|c|c|c|c|c|c|}
\hline & \multicolumn{2}{|c|}{$\begin{array}{l}\text { Medical endoscopist } \\
(n=1522)\end{array}$} & \multicolumn{2}{|c|}{$\begin{array}{l}\text { Nurse endoscopist } \\
(n=1487)\end{array}$} & $\mathrm{p}$ Value \\
\hline Patient age (y) & \multicolumn{2}{|c|}{$57.4(17.5)$} & \multicolumn{2}{|c|}{$58.8(16.8)$} & $0.02 *$ \\
\hline \multicolumn{6}{|l|}{ Patient sex } \\
\hline Male & 679 & $(45 \%)$ & 721 & $(49 \%)$ & $0.04 \dagger$ \\
\hline Female & 843 & (55\%) & 766 & (51\%) & \\
\hline \multicolumn{6}{|l|}{ Indication for endoscopy§ } \\
\hline Dyspepsia & 853 & $(56 \%)$ & 890 & $(60 \%)$ & $0.04 \dagger$ \\
\hline Dysphagia & 123 & $(8 \%)$ & 109 & $(7 \%)$ & $0.48+$ \\
\hline Anaemia & 225 & $(15 \%)$ & 239 & $(16 \%)$ & $0.35 t$ \\
\hline Haematemesis/melaena & 206 & (14\%) & 159 & (11\%) & $0.02 \dagger$ \\
\hline 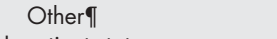 & 294 & (19\%) & 318 & $(21 \%)$ & $0.17 \dagger$ \\
\hline \multicolumn{6}{|l|}{ Inpatient status } \\
\hline Inpatient & 299 & $(20 \%)$ & 283 & (19\%) & $0.70 t$ \\
\hline Outpatient & 1223 & $(80 \%)$ & 1204 & (81\%) & \\
\hline \multicolumn{6}{|l|}{ Endoscope intubation } \\
\hline Successful & 1505 & $(99 \%)$ & 1479 & $(99 \%)$ & $0.12 \ddagger$ \\
\hline Failure & 17 & $(1 \%)$ & 8 & $(1 \%)$ & \\
\hline \multicolumn{6}{|l|}{ Diagnosis } \\
\hline Significant disease ** & 432 & $(29 \%)$ & 463 & (31\%) & \\
\hline Incidental diseaset† & 540 & $(36 \%)$ & 574 & (39\%) & $0.006 t$ \\
\hline Normal & 533 & $(35 \%)$ & 442 & $(30 \%)$ & \\
\hline \multicolumn{6}{|c|}{ Biopsy for pathological assesment } \\
\hline Yes & 419 & $(28 \%)$ & 418 & $(28 \%)$ & $0.83+$ \\
\hline No & 1086 & $(72 \%)$ & 1061 & (72\%) & \\
\hline \multicolumn{6}{|l|}{ Biopsy for rapid urease test } \\
\hline Yes & 453 & $(20 \%)$ & 369 & $(25 \%)$ & $0.002 \dagger$ \\
\hline No & 1052 & (70\%) & 1110 & $(75 \%)$ & \\
\hline \multicolumn{6}{|c|}{$\begin{array}{l}\text { Results relating to patient age are expressed as means }(S D) \text {. } \\
\text { *Student's } t \text { test; } \dagger \chi^{2} \text { test; } \neq \text { Fisher's exact test. } \\
\S \text { Some patients had more than one indication for endoscopy and thus percentages do not total } 100 \% \text {. } \\
\text { IIncludes weight loss, assessment of radiological abnormality, disease follow up, and assessment of } \\
\text { diarrhoea. } \\
\text { **Includes cancer, Barrett's oesophagus, oesophagitis, benign stricturing disease, oesophageal or gastric } \\
\text { varices, peptic ulcer disease, and vascular lesions. } \\
\dagger \dagger \text { Includes hiatus hernia, gastric polyps, gastritis, and duodenitis. }\end{array}$} \\
\hline
\end{tabular}

aspects of gastroscopy under the guidance of a consultant supervisor and each had performed in excess of 150 supervised upper gastrointestinal endoscopies before the study commenced. Consent was obtained from the patient by the endoscopist who performed the procedure and sedation use was determined by individual patient preference. Medical personnel administered all medications as the British Society of Gastroenterology does not currently recommend that nurses administer sedation. ${ }^{9}$ A medical endoscopist was in the vicinity of the endoscopy department at all times to prescribe and administer sedation, to provide endoscopic advice as necessary, and in case of complications. Further follow up was at the discretion of the endoscopist who performed the procedure.

\section{Statistical analysis}

Continuous data are expressed as means (SD) and differences between means were assessed using the Student's $t$ test. Differences between proportions were assessed with the $\chi^{2}$ test or Fisher's exact test, as appropriate. Linear regression analysis with backward elimination of non-significant variables was performed to determine factors independently associated with continuous data such as patient discomfort during endoscope insertion and during the examination. Logistic regression analysis with backward elimination of variables was used to identify factors associated with binary categorical data such as the presence or absence of significant disease and preference for future sedation. All analyses were performed using the Statistical Package for the Social Sciences (SPSS, Chicago, Illinois, USA).

\section{RESULTS}

\section{Indications and diagnoses}

No patient refused endoscopy by either a nurse or medical endoscopist. The clinical features and endoscopic findings of both patient groups are shown in table 1 . There were statistically significant but small differences between endoscopist type and patient age and patient sex. There were no complications in either group and intubation was unsuccessful in 25 cases. Nurses reported fewer endoscopies as "normal" and performed fewer rapid urease tests than medical endoscopists. Table 2 shows factors associated with the presence of significant disease at endoscopy. Male sex, older age, inpatient status, dysphagia, and gastrointestinal bleeding were all associated with the presence of significant disease. In contrast, anaemia was negatively associated with significant endoscopic disease, perhaps because many of these procedures were performed on patients requiring duodenal biopsies to confirm or rule out coeliac disease. Endoscopist type was not associated with finding significant disease and this variable was excluded from the multivariate regression model.

\section{Apprehension, sedation, discomfort, and satisfaction}

Table 3 shows the relationship between endoscopist type and clinical features, pre- endoscopic features, discomfort, and postprocedure patient attitudes in the 480 patients included in the prospective study. Patients in both groups were well matched for age, sex, previous endoscopic experience, pre-procedure fasting, pre-procedure apprehension, and sedation wishes. Patients endoscoped by medical staff under sedation received a mean of $4.9 \mathrm{mg}$ midazolam (SD 2.1) and those endoscoped by nurses a mean of $4.4 \mathrm{mg}$ (SD 1.1) $(\mathrm{p}=0.06)$. There were no differences in post-procedure attitudes in those patients examined by medical or nurse endoscopists. Linear regression analysis showed that discomfort during endoscope insertion was associated with unsedated endoscopy, female sex, and pre-endoscopic apprehension, and was inversely related to patient age (table 4). Discomfort during the subsequent procedure was also associated 
Table 2 Binary logistic regression analysis of factors associated with detecting serious disease in 2984 patients undergoing routine upper gastrointestinal endoscopy (patients whose examinations were unsuccessful were excluded from analysis)

\begin{tabular}{|c|c|c|c|c|}
\hline & Beta & SE beta & Odds ratio $(95 \% \mathrm{Cl})$ & $\mathrm{p}$ Value. \\
\hline Male sex & 0.521 & 0.082 & $1.68(1.43-1.98)$ & $<0.001$ \\
\hline $\mathrm{Age}^{*}$ & 0.009 & 0.002 & 1.01 (1.00-1.01) & $<0.001$ \\
\hline Inpatient status & 0.348 & 0.109 & $1.42(1.15-1.75)$ & 0.001 \\
\hline Dysphagia & 0.589 & 0.145 & 1.80 (1.36-2.39) & $<0.001$ \\
\hline Anaemia & -0.256 & 0.121 & 0.77 (0.61-0.98) & 0.03 \\
\hline Haematemesis/melaena & 0.558 & 0.127 & $1.75(1.36-2.24)$ & $<0.001$ \\
\hline Constant & -1.775 & 0.156 & 0.17 & $<0.001$ \\
\hline
\end{tabular}

Table 3 Relationship between endoscopist type and clinical features, pre-endoscopic features, discomfort, and post-procedure patient attitudes in 480 patients attending for routine diagnostic gastroscopy

\begin{tabular}{|c|c|c|c|}
\hline & $\begin{array}{l}\text { Medical endoscopist } \\
(\mathrm{n}=237)\end{array}$ & $\begin{array}{l}\text { Nurse endoscopist } \\
(n=243)\end{array}$ & $\mathrm{p}$ Value \\
\hline Age (y) & $53.8(16.8)$ & $55.1(15.9)$ & $0.40 *$ \\
\hline \multicolumn{4}{|l|}{ Patient sex } \\
\hline Male & $101 \quad(43 \%)$ & $106 \quad(44 \%)$ & $0.90 t$ \\
\hline Female & $136 \quad(57 \%)$ & $137 \quad(56 \%)$ & \\
\hline Previous sedated endoscopy & $152(65 \%)$ & $153(63 \%)$ & $0.77 \dagger$ \\
\hline Pre-endoscopic fasting $(\mathrm{h})$ & $12.0(3.6)$ & $12.1(5.0)$ & $0.90^{*}$ \\
\hline Pre-endoscopic anxiety & $4.0(3.1)$ & $4.1(2.9)$ & 0.61 * \\
\hline Sedation given & $93(39 \%)$ & $99 \quad(41 \%)$ & $0.81 \dagger$ \\
\hline Discomfort during intubation & $3.7(2.9)$ & $3.7(2.9)$ & $0.97 *$ \\
\hline Discomfort during subsequent procedure & $2.9(2.7)$ & $3.0(2.7)$ & 0.90 * \\
\hline \multicolumn{4}{|l|}{ Examination rating } \\
\hline Worse than expected & 32 (14\%) & $(15 \%)$ & \\
\hline Same as expected & $88 \quad(37 \%)$ & $86 \quad(35 \%)$ & $0.79 \ddagger$ \\
\hline Better than expected & $117 \quad(50 \%)$ & $120 \quad(50 \%)$ & \\
\hline Preference for future sedation & $104 \quad(44 \%)$ & $(44 \%)$ & 0.97 \\
\hline \multicolumn{4}{|c|}{$\begin{array}{l}\text { Results are expressed as means (SD). } \\
\text { *Student's } t \text { test; } † \chi^{2} \text { test; } ¥ \chi^{2} \text { test for trend. } \\
\text { IDue to rounding percentages do not total } 100 \% \text {. }\end{array}$} \\
\hline
\end{tabular}

Table 4 Factors affecting patient discomfort during intubation and during the examination in 480 patients attending for routine diagnostic upper gastrointestinal endoscopy, as assessed by linear regression analyses with backward elimination of variables

\begin{tabular}{|c|c|c|c|}
\hline & $\begin{array}{l}\text { Regression coefficient } \\
(95 \% \mathrm{Cl})\end{array}$ & Beta & $\mathrm{p}$ Value \\
\hline \multicolumn{4}{|l|}{ Discomfort during intubation } \\
\hline Unsedated endoscopy & $2.39(1.89-2.88)$ & 0.40 & $<0.001$ \\
\hline Age $^{*}$ & $-0.03(-0.05$ to -0.02$)$ & -0.17 & $<0.001$ \\
\hline Female sex & $0.64(0.14-1.14)$ & 0.11 & 0.01 \\
\hline Anxiety about examination & 0.09 (0.01-0.18) & 0.10 & 0.03 \\
\hline Constant & $3.20(2.20-4.20)$ & & $<0.001$ \\
\hline \multicolumn{4}{|l|}{ Discomfort during examination } \\
\hline Unsedated endoscopy & $2.50(2.04-2.95)$ & 0.45 & $<0.001$ \\
\hline $\mathrm{Age}^{\star}$ & $-0.02(-0.04$ to -0.01$)$ & -0.16 & $<0.001$ \\
\hline Female sex & $0.65(0.20-1.09)$ & 0.12 & 0.005 \\
\hline Constant & 2.57 (1.71-3.42) & & $<0.001$ \\
\hline
\end{tabular}

with unsedated endoscopy, female sex, and age. Binary logistic regression analysis showed that older patient age and sedation were the only factors independently associated with rating the examination as better than expected (table 5).

\section{DISCUSSION}

The concept of the nurse practitioner originated in the 1960s in America, ${ }^{10}$ and it was envisaged that "advanced nurses" would be trained in patient interviewing techniques, physical examination, diagnosis, and therapeutics. ${ }^{11}$ Over the past 35 years their role has grown to include many areas of primary, secondary, and tertiary health care. ${ }^{12}{ }^{13}$ Nurse practitioners first began performing endoscopic procedures in the early $1970 s,{ }^{14}$ and their role expanded following recommendations from American health care organisations that average risk subjects be regularly screened for colorectal cancer using flexible sigmoidoscopy. ${ }^{15}{ }^{16}$ Subsequent studies indicated that non-medical endoscopists could learn the range of technical 
Table 5 Multivariate analyses of factors associated with patients rating the examination as better than expected

\begin{tabular}{lcllc}
\hline & Beta & SE beta & Odds ratio $(95 \% \mathrm{Cl})$ & $\mathrm{p}$ Value \\
\hline Age $^{*}$ & 0.01 & 0.01 & $1.01(1.00-1.02)$ & 0.03 \\
Sedated endoscopy & 0.67 & 0.19 & $1.95(1.34-2.84)$ & $<0.001$ \\
Constant & -0.96 & 0.34 & 0.38 & 0.005 \\
\hline
\end{tabular}

$\mathrm{SE}$, standard error; $\mathrm{Cl}$, confidence intervals.

*Entered as a continuous variable.

and diagnostic skills needed to perform flexible sigmoidoscopy as safely, effectively, and with similar patient discomfort as gastroenterologists and surgeons. ${ }^{47-20}$ As a result, the British Society of Gastroenterology and the American Society for Gastrointestinal Endoscopy both support nurses performing sigmoidoscopy. ${ }^{21}$ Some nurses also perform full colonoscopy in the $\mathrm{UK}^{22}$ and America, ${ }^{23}$ and preliminary studies show that they carry out both diagnostic and therapeutic procedures safely, effectively, and with adequate caecal and ileal intubation rates. ${ }^{24} 25$

The nurse practitioner grade has developed rapidly over the past 10 years in the $\mathrm{UK}^{26}$ to encompass upper gastrointestinal endoscopy, and recent surveys suggest that there are over 60 nurse endoscopists performing upper gastrointestinal examinations in the UK. ${ }^{22}$ However, there have been no data available with which to evaluate their clinical performance or assess patient satisfaction with examinations performed by them. The nurse endoscopists in our study experienced no particular technical problems during routine gastroscopy for a variety of clinical indications and failure rates were similar in both nursing and medical groups. In addition, the range of endoscopic diseases encountered in their clinical practice was similar to that seen by medical staff. Nevertheless, it cannot be assured that nurse or medical endoscopists did not miss some abnormalities during the study period. Discomfort and satisfaction scores were also similar in groups examined by nursing and medical staff and our findings are comparable with similar flexible sigmoidoscopy outcome studies. ${ }^{18} 20$

The nurse endoscopists in our study were experienced in upper gastrointestinal examinations and had received training both within the unit and on approved courses outside the Trust. In addition to performing the procedure, they discussed the benefits and risks of the examination with patients, obtained informed consent, completed endoscopy reports, discussed diagnoses, provided further advice, and arranged follow up clinic visits as necessary. However, they did not administer sedation, which somewhat compromises the cost effectiveness of nurse endoscopy, especially if performed in single examination room units. Yet studies show that nurses can safely prescribe and administer conscious sedation independently of medical staff ${ }^{2728}$ and the introduction of structured upper gastrointestinal endoscopy programmes which contain sedation modules, such as the course allied to the University of Hull (ENB A87), may resolve this problem. In addition, by study design and British Society of Gastroenterology guideline constraints, our nurses did not perform any endoscopic interventions other than take biopsies for histological analysis or rapid urease testing. However, some nurse endoscopists do perform oesophageal dilatation and stent insertion, variceal injection and banding, ulcer injection, and percutaneous endoscopic gastrostomy tube placement. ${ }^{23} 2429$ There is no ad priori reason why properly trained non- medical staff should not perform certain procedures with the same competence as medical staff, and it is clear that the nurse endoscopist role has not yet been fully defined by interested nursing and medical bodies.

There are limitations to the validity of this clinical observational study. The first part utilised an endoscopic database and is therefore subject to potential referral and selection biases. ${ }^{30}$ In addition, 15 physicians and surgeons were involved in performing endoscopic procedures during the 20 month study period, reflecting day to day clinical practice in a busy endoscopy unit. It is probable that there were at least some variations in performance between the different medical endoscopists who performed a total of 1522 routine procedures in total, compared with the nursing staff who performed a relatively higher volume over the study period. However, as a group there were few differences between the medical and nursing staff employed in this study. Finally, although the discomfort and satisfaction component of this study was performed in a prospective manner, patients were not formally randomised but rather allocated to routine endoscopy lists as they presented to the unit. Thus although the two groups in our prospective study were well matched, we cannot be certain that our results were not biased in some way. In spite of these limitations, our clinical outcomes study does provide useful information on the effectiveness of day to day clinical practice within a contemporary endoscopic unit that could not be extrapolated from tightly structured controlled trials. Our results suggest that experienced nurse endoscopists can perform upper gastrointestinal endoscopy safely and effectively and that there are few differences between medical and nurse endoscopists with regard to certain performance measures such as intubation rates, diagnoses, discomfort scores, and satisfaction ratings following the procedure.

\section{ACKNOWLEDGEMENTS}

The authors would like to acknowledge the kind help of the surgeons, gastroenterologists, hepatologists, and nursing staff in King's College Hospital who assisted during the period of this study. They are also grateful to Adele Gruber and to John Mulcahy and Martha Ellison for helpful advice during manuscript preparation.

\section{Authors' affiliations}

S Smale, I Bjarnason, I Forgacs, P Prasad, M Mukhood, M Wong, A Ng, H E Mulcahy, Department of Gastroenterology, King's College Hospital, Denmark Hill, London, UK

\section{REFERENCES}

1 Quine MA, Bell GD, McCloy RF, et al. Prospective audit of upper gastrointestinal endoscopy in two regions of England: safety, staffing, and sedation methods. Gut 1995;36:462-7.

2 Mokhashi MS, Hawes RH. Struggling toward easier endoscopy. Gastrointest Endosc 1998:48:432-40.

3 NHS Management Executive. Junior doctors. The new deal. London: NHS Management Executive, 1991.

4 Duthie GS, Drew PJ, Hughes MA, et al. A UK training programme for nurse practitioner flexible sigmoidoscopy and a prospective evaluation of the practice of the first UK trained nurse flexible sigmoidoscopist. Gut 1998:43:711-14.

5 Levine DF, Teague RH. A UK training programme for nurse practitioner flexible sigmoidoscopy. Gut 1999;44:897.

6 Mulcahy HE, Greaves RRSH, Ballinger A, et al. A double-blind randomised trial of low versus high dose topical anaesthesia in unsedated upper gastrointestinal endoscopy. Aliment Pharm Therap 1996:10:975-9.

7 Mulcahy HE, Riches A, Kiely $M$, et al. A randomised trial of $6.0 \mathrm{~mm}$ and $9.8 \mathrm{~mm}$ endoscopy in unsedated upper gastrointestinal endoscopy. Endoscopy 2001;33:311-16 
8 Mulcahy HE, Kelly P, Banks MR, et al. Factors associated with tolerance to, and discomfort with, unsedated diagnostic gastroscopy. Scand J Gastroenterol 2001:36:1352-7.

9 British Society of Gastroenterology Endoscopy Section Working British Society of Gastroenterology Endoscopy
Party. The nurse endoscopist. Gut 1995;36:795.

10 Wilson D. Nurse practitioners: the early years (1965-1974). Nurse Pract 1994; 19:26-8.

11 National Organisation of Nurse Practitioner Faculties Education Committee. Advanced Nursing Practice: Nurse Practitioner Curriculum Guidelines: Final Report, April, 1990. Seattle: National Organisation of Nurse Practitioner Faculties, 1990.

12 Thrasher $\mathbf{C}$. The primary care nurse practitioner: advocate for self care. J Am Acad Nurse Pract 2002;14:113-17.

13 Nagle CW, Perlmutter DF. The evolution of the nurse practitioner role in the neonatal intensive care unit. Am J Perinatol 2000;17:225-8.

14 Spencer RJ, Ready RL. Utilisation of nurse endoscopists for sigmoidoscopic examinations. Dis Colon Rectum 1977;20:94-6.

15 National Cancer Institute. Working Guidelines for Early Cancer Detection: Rationale and Supporting Evidence to Decrease Mortality. Bethesda: National Cancer Institute, 1987.

16 American Cancer Society. Summary of Current Guidelines for the Cancer Related Checkup: Reccomendations. New York: American Cancer Society, 1989

17 Schoenfeld P, Lipscomb S, Crook J, et al. Accuracy of polyp detection Schoenfeld $\mathbf{P}$, Lipscomb $S$, Crook J, et al. Accuracy of polyp
by gastroenterologists and nurse endoscopists during flexible sigmoidoscopy: a randomized trial. Gastroenterology 1999;117:312-8.

18 Schoenfeld PS, Cash B, Kita J, et al. Effectiveness and patient satisfaction with screening flexible sigmoidoscopy performed by registered nurses. Gastrointest Endosc 1999;49:158-62.

19 Schoen RE, Weissfeld JL, Bowen NJ, et al. Patient satisfaction with screening flexible sigmoidoscopy. Arch Intern Med 2000;160:1790-6.
20 Maule WF. Screening for colorectal cancer by nurse endoscopists. $N$ Engl J Med 1994;330:183-7.

21 Endoscopy by non-physicians: Guidelines for clinical application Gastrointest Endosc 1999;49:826-8.

22 Pathmakanthan S, Murray I, Smith K, et al. Nurse endoscopists in United Kingdom health care: a survey of prevalence, skills and attitudes. J Adv Nurs 2001;36:705-10

23 Brooks D, Cash MD, Schoenfeld S, et al. Licensure, use and training of paramedical personnel to perform screening flexible sigmoidoscopy. Gastrointest Endosc 1999:49:163-9.

24 Pathmakanthan S, Smith K, Thompson G, et al. A comparison of nurse and doctor performed colonoscopy. Gut 2002;50:A102.

25 Vance ME, Shah SG, Suzuki N, et al. Nurse colonoscopy: A review of 160 cases. Gut 2002;50:A98.

26 Department of Health and Social Security. The Extending Role of the Clinical nurse. Legal Implications and Training Requirements. London: DHSS, 1997.

27 Sury MR, Hatch DJ, Deeley T, et al. Development of a nurse-led sedation service for paediatric magnetic resonance imaging. Lancet 1999:353:1667-71.

28 Natale A, Kearney MM, Brandon M, et al. Safety of nurse-administered deep sedation for defibrillator implantation in the electrophysiology laboratory. J Cardiovasc Electrophysiol 1996;7:301-6.

29 Sturgess RP, O'Toole PA, McPhillips J, et al. Percutaneous endoscopic gastrostomy: evaluation of insertion by an endoscopy nurse practitioner. Eur J Gastroenterol Hepatol 1996;8:631-4.

30 Eisen G. Endoscopic databases and outcomes research. Gastrointest Endosc Clin N Am 1999:4:587-94. 